\title{
Estimation of Coda Wave Attenuation Quality Factor from Digital Seismogram Using Statistical Approach
}

\author{
Jwngsar Brahma
}

School of Petroleum Technology, Pandit Deendayal Petroleum University, Gandhinagar, 382007, India

\begin{abstract}
The main objective of the paper is to estimate seismic wave attenuation from the decay rate of coda wave amplitudes of digital seismogram of local earthquakes (epicentral distance $<100 \mathrm{~km}$ ) following statistical approach. Three earthquake events have been selected for estimation of coda wave attenuation quality factor $\left(\mathrm{Q}_{\mathrm{c}}\right)$. The coda wave of 9 seismograms from 3 local earthquakes recorded digitally by three seismic stations in the region have been analyzed for this purpose at ten central frequencies $(1,1.5,2,3,4,6,8,12,16$ and $18 \mathrm{~Hz})$ and three lapse time windows of 20, 30 and 40 seconds duration. Single backscattering model proposed by Aki (1969) and extended by Aki and Chouet (1975) and Sato (1977) is employed to determine $Q_{c}$ values. The mean values of the estimated $Q_{c}$ vary from $31 \pm 12($ at $1 \mathrm{~Hz})$ to $1974 \pm 211$ (at $18 \mathrm{~Hz})$ for 20 seconds coda window length. For 30 seconds coda window length $Q_{c}$ vary from $46 \pm 16($ at $1 \mathrm{~Hz})$ to $1977 \pm$ 256 (at $18 \mathrm{~Hz}$ ). Similarly for 40 seconds coda window length $Q_{c}$ vary from $97 \pm 22$ to $2552 \pm 312$. It is observed that $Q_{c}$ value for the study area is frequency dependent and increase with increase in frequency. Moreover the observed $\mathrm{Q}_{c}$ values increase with increasing lapse time at all frequency bands. The estimated $\mathrm{Q}_{c}$ values show a frequency dependent relationship of the form $\mathrm{Q}_{c}=\mathrm{Q}_{0} \mathrm{f}^{\mathrm{n}}$, where $\mathrm{Q}_{0}$ is $\mathrm{Q}_{\mathrm{c}}$ at $1 \mathrm{~Hz}$ and $\mathrm{n}$ represents degree of frequency dependence. The frequency dependent empirical attenuation relationship for 20,30 and 40 seconds window lengths are obtained as $\mathrm{Q}_{\mathrm{c}}=21.49+1.17 f^{1.48+0.08}, \mathrm{Q}_{\mathrm{c}}=$ $48.6+1.11 f^{1.29+0.06}$ and $\mathrm{Q}_{\mathrm{c}}=88.86+1.12 f^{1.19+0.06}$ respectively.
\end{abstract}

Keywords Earthquake, Seismogram, Coda Waves, Central Frequency, Epicentral Distance, Local Earthquake

\section{Introduction}

Attenuation is one of the fundamental properties of seismic waves from which the material and physical conditions in the Earth's interior can be inferred (Aki, 1980). The decay of seismic wave amplitude with distance defines the attenuation of the medium. Seismic attenuation is usually considered to be a combination of two mechanisms - intrinsic absorption and scattering loss. As seismic wave propagate through the Earth's interior and finally arrives at seismic stations on the surface, its energy (amplitude) decays due to conversion of elastic energy to heat or other forms of energy (intrinsic attenuation) as well as energy redistribution in the heterogeneities present in the lithosphere (scattering). The measurement and interpretation of elastic wave attenuation is important for studying the medium through which seismic wave propagates.

Attenuation of seismic wave is described by a dimensionless parameter called the quality factor Q (Knopoff, 1964) that expresses the wave amplitude decay that occurs when a wave propagates through a medium the

* Corresponding author:

Jwngsar@gmail.com (Jwngsar Brahma)

Published online at http://journal.sapub.org/scit

Copyright (C) 2012 Scientific \& Academic Publishing. All Rights Reserved inverse of the quality factor $\left(\mathrm{Q}^{-1}\right)$ is known as the attenuation factor, which is proportional to decay of amplitude with passages of time or source- receiver distance. The attenuation quality factor $(\mathrm{Q})$ is a combination of intrinsic quality factor, $Q_{\mathrm{i}}$ and scattering quality factor $\mathrm{Q}_{\mathrm{s}}$.

There are various methods to estimate the attenuation quality factor of seismic wave in a region. It is difficult to measure attenuation from a high frequency seismogram using a deterministic approach, because large number of parameters is required to adequately explain a high frequency seismogram. In order to overcome this difficulty Aki (1969) initiated the application of a statistical approach to study of high frequency seismic waves. All portions of a seismogram cannot be treated entirely statistically, because their characters are determined by a particular nature of the path between the source and station (Aki, 1969). Aki (1969), developed a model for the rate of coda decay and suggested that the seismic coda waves of local earthquakes are backscattered body waves from numerous randomly distributed heterogeneities in the earth's crust and may be treated by a statistical method. The longer the wave travels the greater the variety of heterogeneities they encountered. The later portions of a seismogram therefore may be considered as a result of some kind of averaging over many samples of heterogeneities, thus suggesting a statistical treatment in which a small number of parameters characterize the average prop- 
erties of the heterogeneous medium (Aki and Chouet, 1975). One of the most promising means of studying seismic scattering and attenuation in the crust and lithosphere is analysis of the coda of local earthquake (Aki, 1969). Coda is the end part of a seismogram of locally recorded earthquake following the body and surface waves containing a very complex and gradually decaying signal. The coda wave amplitude on a seismogram is explained by two backscattering models (Aki and Chouet, 1975).

The first is the single scattering model, according to which waves are backscattered $\mathrm{S}$ waves and generated when $\mathrm{S}$ wave encounters different heterogeneity present in the propagating media. This model assumes that the scattering wave field is weak and does not produce secondary scattering when it encounters another scatterer. The law of energy conservation is violated because of oversimplification of this model. This model assumes that earthquake source and the seismic station are located at the same point in an unbounded, homogenous, and isotropic medium containing a random but uniform spatial distribution of heterogeneities. This model was further modified by Sato (1977), considering a finite distance separating the source and receiver.

The second model is the multiple scattering models (Aki and Chouet, 1975; Gao et al., 1983a), which assumes secondary scattering and consider the seismic energy transfer as a diffusion process. Aki (1969) suggested that coda $\mathrm{Q}_{c}{ }^{-1}$ is more closely related to intrinsic rather than scattering attenuation. Within the frame work of the single scattering theory $\mathrm{Q}_{c}{ }^{-1}$ represents an effective attenuation, including the contribution of both intrinsic and scattering loss ( Akinci et al., 2000). Several authors (e.g. Aki and Chouet, 1975; Sato, 1977; Rautian and Khalturin, 1978; Hermann, 1098; Roecker et al., 1982; Frankel, 1991; Woodgold, 1992; Gupta, 1998) observed that the coda wave model of Aki (1969), extended by Aki and Chouet (1975) and Sato (1977) is the easiest way to estimate the attenuation, backscattering and source spectrum.

In the present study, $Q_{c}$ is estimated following single scattering model of Aki and Chouet (1975) extended by Sato (1977). The events used in this study are listed in Table $1 . Q_{c}$ is measured as a function of frequency using the digital waveform data of local earthquakes. A study is made of elastic wave attenuation to develop an attenuation relationship. The coda $\mathrm{Q}_{c}$ values are calculated for different lapse time windows of coda envelope to investigate the lapse time dependence of $\mathrm{Q}_{c}$ as well as the possibility of depth dependence of seismic attenuation.

\section{Data}

In this study, we selected only 3 earthquakes given in the Table 1 recorded by local seismic network during the three local seismic stations namely Tezpur (TZR), Dokmok (DMK) and Seijusa (SJA).The broadband seismic stations are equipped with CMG-3T / CMG-3ESP seismometer (3-component) and REFTEK 72A series data acquisition system. The sampling rate of the signal is 100 samples per second. The locations of the seismic stations as well as the epicenters of the earthquake events are shown in Figure 1. The selection of the data set is made on the basis of the following criteria:year 2001. These events are recorded by

i. Epicentral distance of the events less than $100 \mathrm{~km}$

ii. Higher signal to noise ratio.

iii. Clear record of coda wave

Out of two horizontal components of seismograms only one component is utilized for this purpose for which S-wave arrival is earlier compared to the other. Total 9 horizontal component seismograms are selected for this purpose. The hypocentral parameters of the selected events are listed in Table 1.

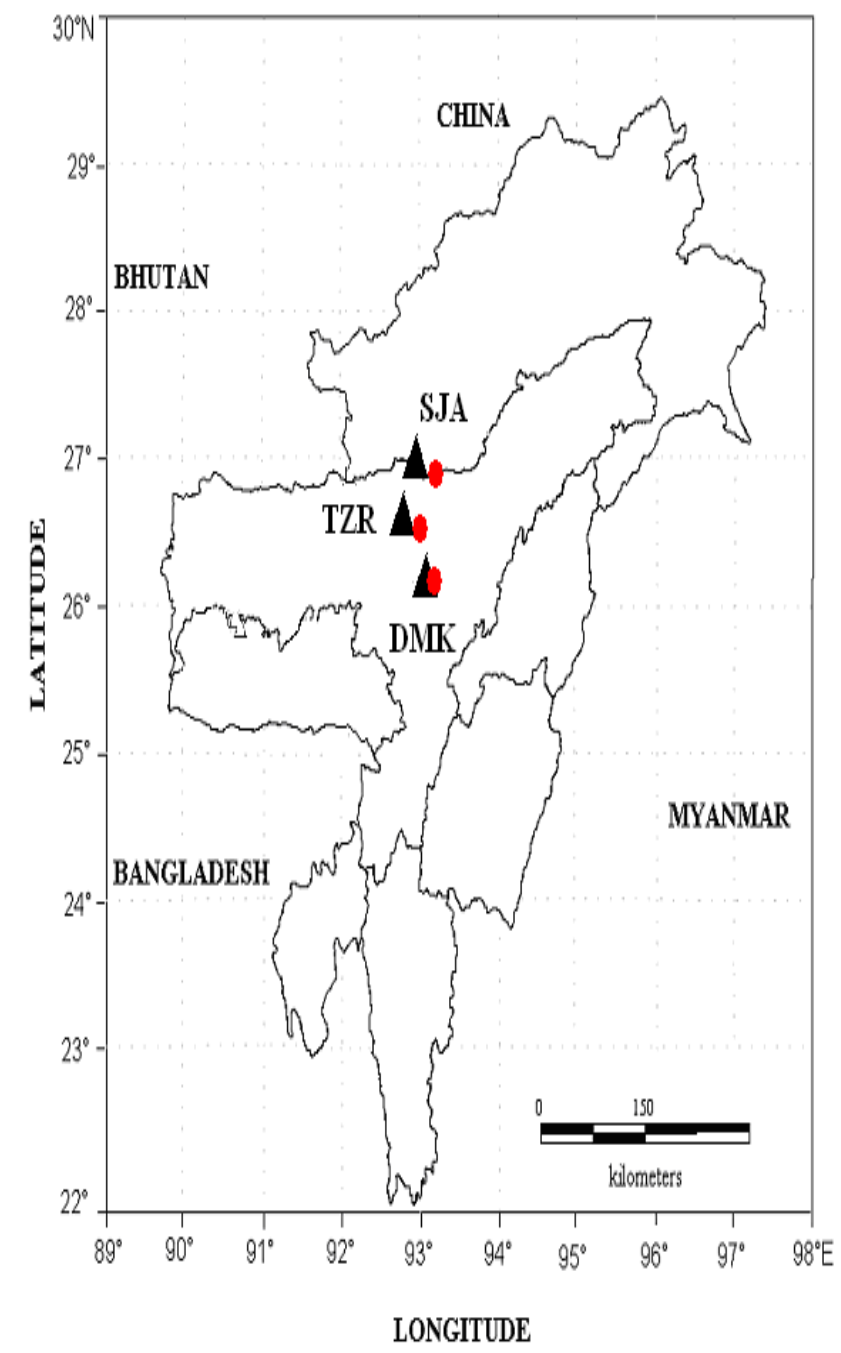

Figure 1. Figure showing location of 3 earthquakes (Red balls) used in the present study and the recording seismograph stations (black triangles) namely Tezpur (TZR), Dokmok (DMK) and Seijusa (SJA)

The signal to noise ratio of each event is estimated. For this purpose the noise and signal power spectra are determined using Fast Fourier Transformation (FFT) algorithm using about 2 seconds long time series before and after the Pwave first arrival. An example for MND station is shown in Figure 2a and Figure $2 b$. 
Table 1. Hypocentral parameters of the events used in this study

\begin{tabular}{ccccccccc}
\hline Sl. No & Date & \multicolumn{3}{c}{ Origin Time } & \multicolumn{2}{c}{ Location } & Focal Depth & Magnitude \\
& & Hr. & Mu. & Sec. & Lat. ${ }^{0} \mathrm{~N}$ & Long. ${ }^{0} \mathrm{~N}$ & $(\mathrm{Km})$ & $\left(\mathrm{M}_{\mathrm{D}} \mathrm{A}\right)$ \\
\hline 1 & 20011120 & 21 & 35 & 04.12 & 26.80 & 93.20 & 9.8 & 3.0 \\
2 & 20011122 & 11 & 53 & 55.98 & 26.37 & 93.11 & 10 & 2.1 \\
3 & 20011118 & 19 & 37 & 26.30 & 26.19 & 93.11 & 35 & 3.4 \\
\hline
\end{tabular}

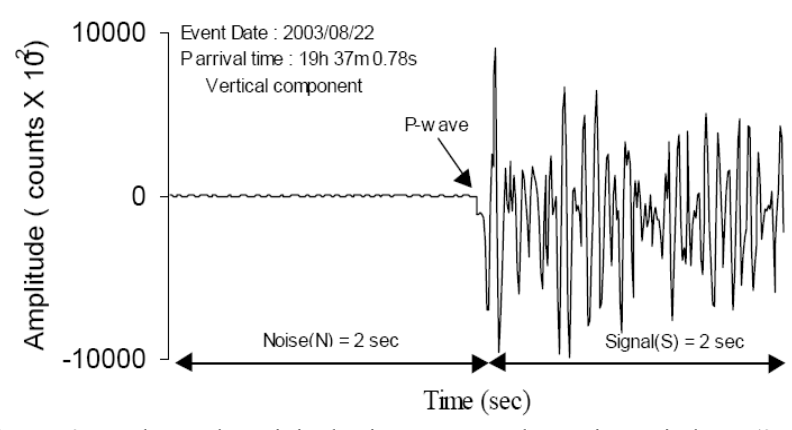

Figure 2a. shows the original seismogram and two time windows (2 sec before and after $\mathrm{P}$ arrival) used in the evaluation

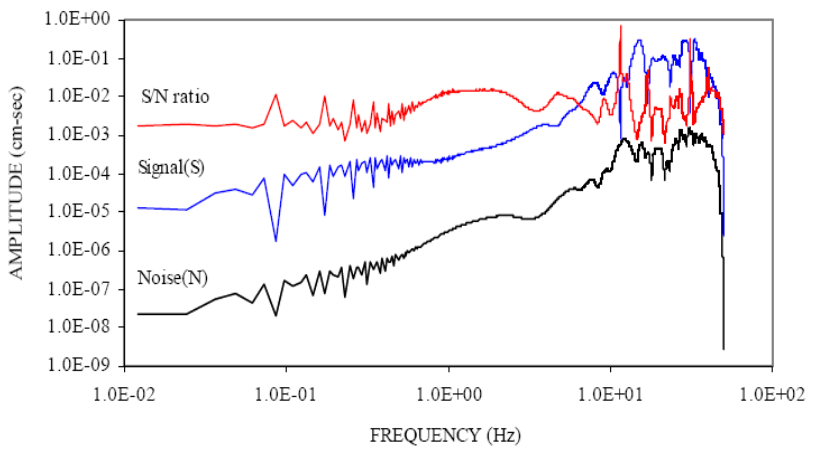

Figure 2b. Shows the corresponding frequency spectra designated as Noise (N)[black], Signal (S)[blue] and S/N ratio [red]

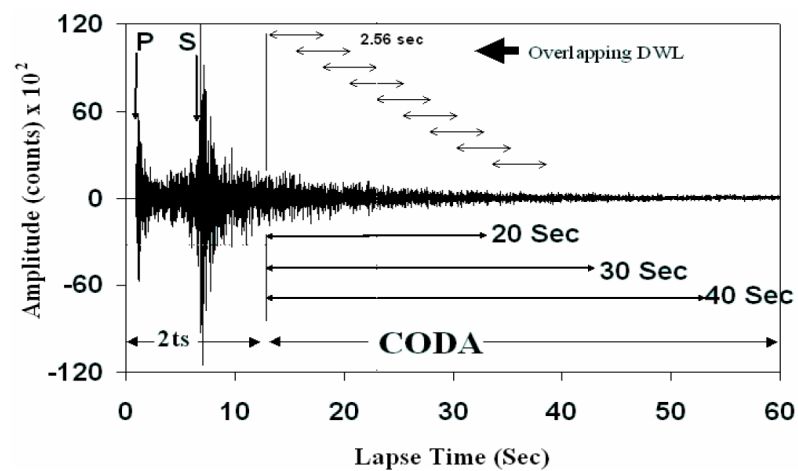

Figure 3. Figure showing a digital seismogram recorded by DMK seismic station. Different coda window length used in this study are shown along with the discrete window length of $2.56 \mathrm{sec}$ used for smoothening the coda envelope by calculating RMS values of coda wave amplitudes with a sliding window of half of the discrete window length i.e. 1.28 seconds

\section{Method and Data Analysis}

The coda Q method was introduced by Aki(1969) and has been extended by different researchers e.g. Aki and Chouet (1975), Sato (1977) and Rautian and Khalturin (1978). We have utilized the single back scattering model developed by
Aki (1969) and extended by Aki and Chouet (1975) and Sato (1977) for estimation of coda wave attenuation quality factor, Q.

This model is based on the following assumptions:

i. Scattering is a weak process and doesn't produce any secondary (multiple) when it encounters anther scatter. This so call Born approximation, which violates the energy conservation law but has been accepted in various physical problems and used successfully in high frequency seismic waves analysis.

ii. As the coda waves arrive long time after arrival of all direct waves ( $p, s$ and surface waves) the source and receiver are assumed to be placed at one point (for coincident).

According to Aki (1969), Aki \& Chouet (1975) and Sato (1977), the time dependence of root mean square coda wave amplitude, $\mathrm{A}(\omega, \mathrm{t})$, on a bandpass-filtered seismogram can be written as

$$
A(\omega, t)=C(\omega) \cdot t^{-1} \exp \left(-\omega t / 2 Q_{c}\right)
$$

where $\mathrm{Q}_{\mathrm{c}}$ is the attenuation quality factor as a function of frequency, $\mathrm{t}^{-1}$ is a correction factor for the geometrical spreading, and $C(\omega)$ takes into account these terms of source and site amplification. This model is believed to be more appropriate for small local earthquake than multiple - scattering model (Ibanez et al., 1990).

Sato (1977) developed the model where root mean square (rms) coda wave amplitude at lapse time $\mathrm{t}$ may be written as

$$
\mathrm{A}(\mathrm{r}, \omega, \mathrm{t})=\mathrm{C}(\omega)[\mathrm{K}(\mathrm{r}, \mathrm{x})] \exp \left(-\omega \mathrm{t} / 2 \mathrm{Q}_{\mathrm{c}}\right.
$$

where, $x=t / t_{s}\left(t_{s}\right.$ is the travel time of $S$ wave) and $r$ is station-source distance; $\mathrm{K}(\mathrm{r}, \mathrm{x})$ is a function of $\mathrm{x}$ and $\mathrm{r}$, defined as

$$
\mathrm{K}(\mathrm{r}, \mathrm{x})=1 / \mathrm{r} \cdot 1 / \mathrm{x} \cdot \ln (\mathrm{x}+1 / \mathrm{x}-1)
$$

By taking the natural logarithms of equation (2) and rearranging terms, we obtain the following equation:

$$
\ln [\mathrm{A}(\mathrm{r}, \omega, \mathrm{t}) /[\mathrm{K}(\mathrm{r}, \mathrm{x})]]=\ln [\mathrm{C}(\omega)]-\left(\omega \mathrm{t} / 2 \mathrm{Q}_{\mathrm{c}}\right)
$$

For narrow bandpass-filtered seismograms, $\mathrm{C}(\omega)$ is constant. Therefore, by using a linear regression of terms on the left side of equation (4) vs t, $Q_{c}$ can be determined from the slope of the fit, which is equal to $-\omega t / 2 Q_{c}$

Table 2. Parameters of band-pass filter showing central frequencies with respective low and high cut off frequencies

\begin{tabular}{|c|c|c|}
\hline Low cutoff $(\mathrm{Hz})$ & Central frequency $(\mathrm{Hz})$ & High cutoff $(\mathrm{Hz})$ \\
\hline 0.67 & 1.0 & 1.33 \\
\hline 1.00 & 1.5 & 2.00 \\
\hline 1.33 & 2.0 & 2.67 \\
\hline 2.00 & 3.0 & 4.00 \\
\hline 2.67 & 4.0 & 5.33 \\
\hline 4.00 & 6.0 & 8.00 \\
\hline 5.33 & 8.0 & 10.67 \\
\hline 8.00 & 12.0 & 16.00 \\
\hline 10.67 & 16.0 & 21.33 \\
\hline 12.00 & 18.0 & 24.00 \\
\hline
\end{tabular}


In order to study the frequency and lapse time dependence of $\mathrm{Q}_{\mathrm{c}}$, we used following scheme to analyze the data:

i. The seismograms are filtered for narrow frequency bands centered at $\mathrm{f}_{\mathrm{c}}=1,1.5,2,3,4,6,8,12,16$ and $18 \mathrm{~Hz}$ respectively using 8 - pole Butterworth band pass filter. The ten frequency bands (bandwidth $0.67 f_{c}$, where $f_{c}$ is the central frequency) with filter parameters are given in Table 2.

ii. The beginning of coda amplitude starts at $2 t_{s}$, where $t_{s}$ is the travel time of $\mathrm{S}$ - wave measured from the origin time of the earthquake (Rautian and Khalturin, 1978).

iii. The filtered coda amplitudes are smoothed by determining Root Mean Squire (RMS) amplitude for sliding window of 2.56 seconds in steps of half of the time window i.e. 1.28 seconds. The RMS amplitude values are assigned to the center point of corresponding window Figure 3.

iv. Once the set of $A(r, \omega, t) /[K(r, x)]$ and the coda intervals are obtained beginning at $2 \mathrm{ts}, \mathrm{Q}_{\mathrm{c}}$ could be easily estimated from the slope of the linear fit of equation (4), $\ln [\mathrm{A}(\mathrm{r}, \omega, \mathrm{t}) /$ $[\mathrm{K}(\mathrm{r}, \mathrm{x})]$ vs. $\mathrm{t}$, the lapse time.

In the next step, the lapse time dependence of $Q_{c}$ is observed by increasing the coda duration step by step, measured from origin time. Each seismogram falling in the lapse time range of 20-90 seconds is analyzed starting at $2 \mathrm{t}_{\mathrm{s}}$. Figure 4a shows an example of original and band pass filtered seismogram (event no. 2 in Table 1) of a local earthquake recorded by the DMK (Dokmok) station and Figure $4 \mathrm{~b}$ shows the plot of $\ln [\mathrm{A}(\mathrm{r}, \omega, \mathrm{t}) /[\mathrm{K}(\mathrm{r}, \mathrm{x})]$ vs. $\mathrm{t}$, the lapse time for $30 \mathrm{sec}$ coda window.
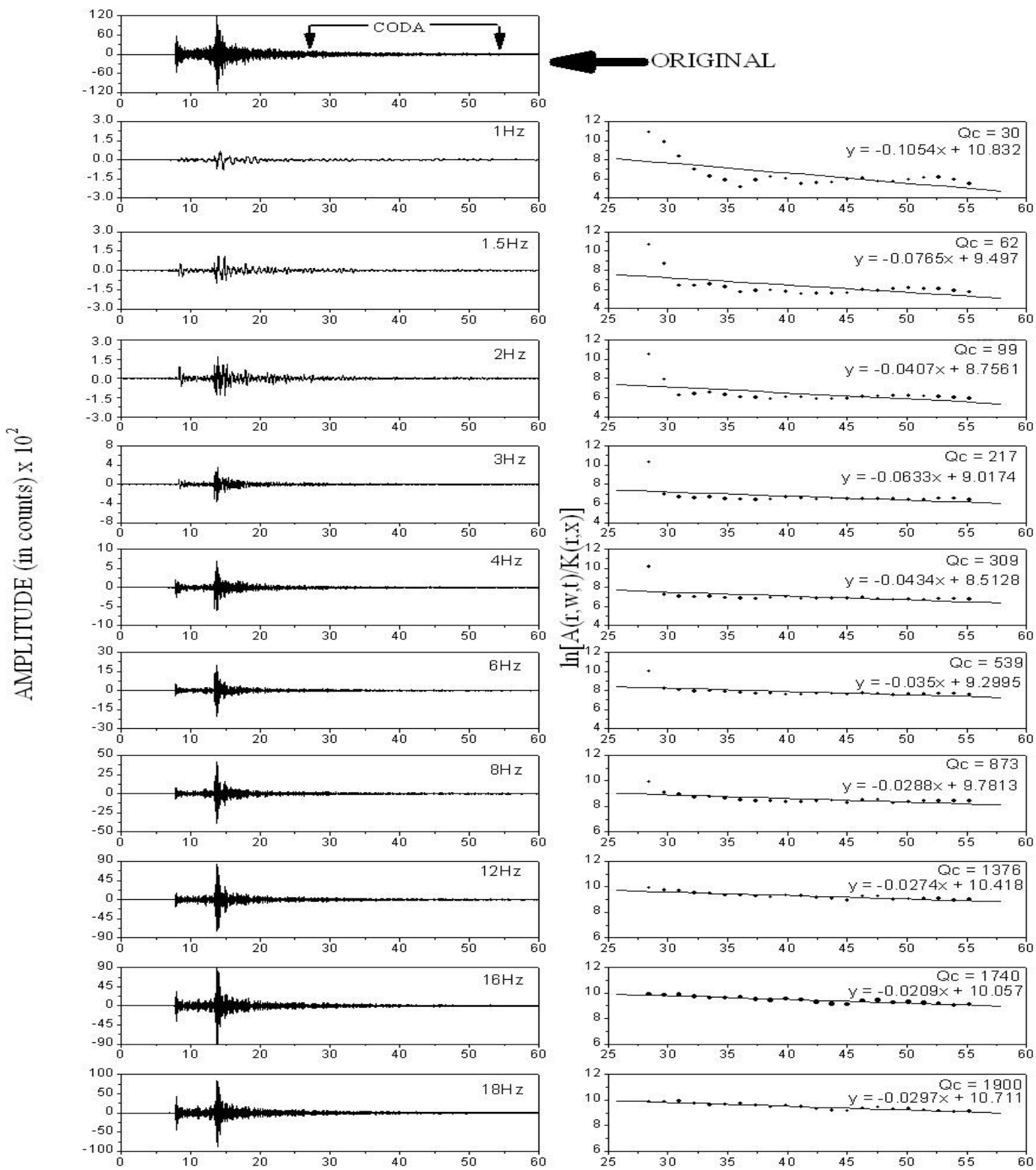

(a)

\section{LAPSE TIME (Sec)}

(b)

Figure 4 (a). Shows an example of original and band pass filtered seismogram (event no. 2 in Table 1) of a local earthquake recorded by the DMK (Dokmok) station and (b) Shows the plot of $\ln [\mathrm{A}(\mathrm{r}, \omega, \mathrm{t}) /[\mathrm{K}(\mathrm{r}, \mathrm{x})]$ vs. t, the lapse time for 30 sec coda window 


\section{Results and Discussion}

The $\mathrm{Q}_{\mathrm{c}}$ values are estimated filtering the coda waves of 9 waveforms in frequency band centered at 1, 1.5, 2, 3, 4, 6, 8, 12,16 and $18 \mathrm{~Hz}$ for lapse time window length of 20,30 and 40 seconds. Total $270 \mathrm{Q}_{\mathrm{c}}$ measurements are obtained for 20 , 30 and 40 seconds coda window length estimated from the linear regression of the $\ln [A(f, t) / K(r, x)]$ vs $t$ plot. The $\mathrm{Q}_{\mathrm{c}}$ values for all lapse time and frequency ranges are listed in Table 3a, Table $3 \mathrm{~b}$ and Table $3 \mathrm{c}$

The $\mathrm{Q}_{\mathrm{c}}$ measurements estimated from $20 \mathrm{sec}$ coda window length vary from 7 to 92 at frequency $1 \mathrm{~Hz}$ and 562 to 5492 at $18 \mathrm{~Hz}$. The distributions of $\mathrm{Q}_{c}$ values with frequency are shown in Figure 5a. The mean value of $\mathrm{Q}_{\mathrm{c}}$ observations (filled circles) using 20 seconds coda window length for all the stations are also shown in the Figure 5a which vary from
$31 \pm 14$ at $1 \mathrm{~Hz}$ to $1974 \pm 209$ at $18 \mathrm{~Hz}$. It is observed from the general trend (Figure 5a) that $\mathrm{Q}_{\mathrm{c}}$ values follows a power law of the from $\mathrm{Q}_{\mathrm{c}}=\mathrm{Q}_{0} \mathrm{f}^{\mathrm{n}}$, where $\mathrm{Q}_{0}$ is the quality factor at $1 \mathrm{~Hz}$ and $n$ is the frequency dependent coefficient. For 20 seconds coda window $\mathrm{Q}_{0}$ and $n$ are $21.49 \pm 1.11$ and $1.48 \pm 0.08$ respectively and we obtain the frequency dependent attenuation relation as $\mathrm{Q}_{\mathrm{c}}=21.49 \pm 1.11 f^{1.48 \pm 0.08}$.

For $30 \mathrm{sec}$ coda window length $\mathrm{Q}_{\mathrm{c}}$ measurements vary from 14 to 115 at frequency $1 \mathrm{~Hz}$ and 1065 to 3400 at $18 \mathrm{~Hz}$. The distributions of $\mathrm{Q}_{c}$ values with frequency are shown in Figure $5 \mathrm{~b}$. The mean value of $\mathrm{Q}_{\mathrm{c}}$ observations (shown by dark filled circles in Figure 5b) vary from $46 \pm 22$ at $1 \mathrm{~Hz}$ to $1977 \pm 225$ at $18 \mathrm{~Hz}$. The empirical attenuation relationship for 30 seconds coda window length is obtained as $\mathrm{Q}_{\mathrm{c}}=69.92$ $\pm 1.11 f^{123 \pm 0.058}$.

Table 3a. The $\mathrm{Q}_{\mathrm{c}}$ values for the three at different stations and lapse time coda window length of event no.1.

\begin{tabular}{|c|c|c|c|c|c|c|c|c|c|}
\hline \multirow{2}{*}{ Frequercy (Hz) } & \multicolumn{6}{|c|}{ Qc values at different stations and lapse time coda window length } \\
\cline { 2 - 11 } & \multicolumn{2}{|c|}{ TZR } & \multicolumn{3}{c|}{ DMK } & \multicolumn{3}{c|}{ SJA } \\
\cline { 2 - 11 } & $20 \mathrm{Sec}$ & $30 \mathrm{Sec}$ & $40 \mathrm{Sec}$ & $20 \mathrm{Sec}$ & $30 \mathrm{Sec}$ & $40 \mathrm{Sec}$ & $20 \mathrm{Sec}$ & $30 \mathrm{Sec}$ & $40 \mathrm{Sec}$ \\
\hline 1 & 7 & 14 & 24 & 15 & 37 & 80 & 32 & 115 & 80 \\
\hline 1.5 & 14 & 33 & 67 & 27 & 79 & 178 & 59 & 332 & 178 \\
\hline 2 & 25 & 70 & 148 & 45 & 153 & 370 & 119 & 599 & 370 \\
\hline 3 & 58 & 184 & 354 & 120 & 354 & 834 & 345 & 600 & 834 \\
\hline 4 & 99 & 305 & 718 & 206 & 474 & 1197 & 497 & 655 & 1197 \\
\hline 6 & 149 & 379 & 1157 & 263 & 789 & 1349 & 545 & 637 & 1349 \\
\hline 8 & 189 & 451 & 1065 & 382 & 830 & 1643 & 603 & 760 & 1643 \\
\hline 12 & 325 & 675 & 1407 & 614 & 1205 & 1813 & 1065 & 1314 & 1813 \\
\hline 16 & 482 & 938 & 2372 & 827 & 1552 & 2206 & 2036 & 1957 & 2206 \\
\hline 18 & 562 & 1065 & 3143 & 921 & 1704 & 2377 & 2254 & 2103 & 2377 \\
\hline
\end{tabular}

Table 3b. The $\mathrm{Q}_{\mathrm{c}}$ values for the three at different stations and lapse time coda window length of event no.2.

\begin{tabular}{|c|c|c|c|c|c|c|c|c|c|}
\hline \multirow{3}{*}{ Frequercy (Hz) } & \multicolumn{6}{|c|}{ Qc values for different stations and lapse time coda window } \\
\cline { 2 - 12 } & \multicolumn{3}{|c|}{ TZR } & \multicolumn{3}{c|}{ DMK } & \multicolumn{3}{c|}{ SJA } \\
\cline { 2 - 11 } & $20 \mathrm{Sec}$ & $30 \mathrm{Sec}$ & $40 \mathrm{Sec}$ & $20 \mathrm{Sec}$ & $30 \mathrm{Sec}$ & $40 \mathrm{Sec}$ & $20 \mathrm{Sec}$ & $30 \mathrm{Sec}$ & $40 \mathrm{Sec}$ \\
\hline 1 & 7 & 16 & 30 & 13 & 30 & 56 & 91 & 90 & 165 \\
\hline 1.5 & 18 & 46 & 88 & 23 & 62 & 111 & 131 & 117 & 168 \\
\hline 2 & 35 & 97 & 192 & 40 & 99 & 183 & 273 & 200 & 203 \\
\hline 3 & 81 & 233 & 499 & 97 & 217 & 334 & 396 & 326 & 314 \\
\hline 4 & 118 & 310 & 655 & 147 & 309 & 437 & 283 & 345 & 414 \\
\hline 6 & 174 & 392 & 702 & 242 & 539 & 704 & 423 & 725 & 1136 \\
\hline 8 & 249 & 528 & 822 & 388 & 873 & 1061 & 783 & 1360 & 1369 \\
\hline 12 & 446 & 941 & 1253 & 804 & 1376 & 1661 & 1831 & 2170 & 2071 \\
\hline 16 & 734 & 1327 & 1586 & 1148 & 1740 & 2149 & 2592 & 2313 & 3291 \\
\hline 18 & 883 & 1513 & 1773 & 1277 & 1905 & 2338 & 4480 & 3400 & 3701 \\
\hline
\end{tabular}

Table 3c. The $\mathrm{Q}_{\mathrm{c}}$ values for the three at different stations and lapse time coda window length of event no.3

\begin{tabular}{|c|c|c|c|cc|c|c|c|c|}
\hline \multirow{2}{*}{ Frequercy (Hz) } & \multicolumn{6}{|c|}{ Qc values for different stations at different lapse time coda window } \\
\cline { 2 - 11 } & \multicolumn{3}{|c|}{ TZR } & \multicolumn{3}{c|}{ DMK } & \multicolumn{4}{|c|}{ SJA } \\
\cline { 2 - 10 } & $20 \mathrm{Sec}$ & $30 \mathrm{Sec}$ & $40 \mathrm{Sec}$ & $20 \mathrm{Sec}$ & $30 \mathrm{Sec}$ & $40 \mathrm{Sec}$ & $20 \mathrm{Sec}$ & $30 \mathrm{Sec}$ & $40 \mathrm{Sec}$ \\
\hline 1 & 7 & 14 & 25 & 13 & 35 & 60 & 92 & 64 & 357 \\
\hline 1.5 & 15 & 35 & 64 & 27 & 74 & 125 & 139 & 130 & 536 \\
\hline 2 & 30 & 69 & 116 & 46 & 126 & 206 & 224 & 234 & 551 \\
\hline 3 & 63 & 112 & 237 & 106 & 239 & 37 & 439 & 446 & 693 \\
\hline 4 & 94 & 117 & 328 & 174 & 332 & 433 & 635 & 454 & 990 \\
\hline 6 & 141 & 278 & 414 & 362 & 577 & 612 & 1217 & 659 & 1193 \\
\hline 8 & 205 & 400 & 640 & 699 & 1056 & 895 & 1722 & 982 & 1316 \\
\hline 12 & 368 & 664 & 1003 & 1429 & 1485 & 1305 & 2357 & 1539 & 1964 \\
\hline 16 & 548 & 976 & 1425 & 1876 & 1876 & 1783 & 3104 & 2296 & 2941 \\
\hline 18 & 632 & 1157 & 1697 & 2050 & 2135 & 2006 & 3697 & 2814 & 3558 \\
\hline
\end{tabular}


Similarly, the distribution of $\mathrm{Q}_{\mathrm{c}}$ estimates using $40 \mathrm{Sec}$ window length is shown in Figure $5 \mathrm{c}$. The mean value of $\mathrm{Q}_{\mathrm{c}}$ estimates at 40 seconds vary from $97 \pm 34$ at $1 \mathrm{~Hz}$ to $2552 \pm$ 685 at $18 \mathrm{~Hz}$. The empirical attenuation relationship from these $\mathrm{Q}_{\mathrm{c}}$ values are obtained as $\mathrm{Q}_{\mathrm{c}}=88.86 \pm 1.12 f^{1.19+0.06}$.

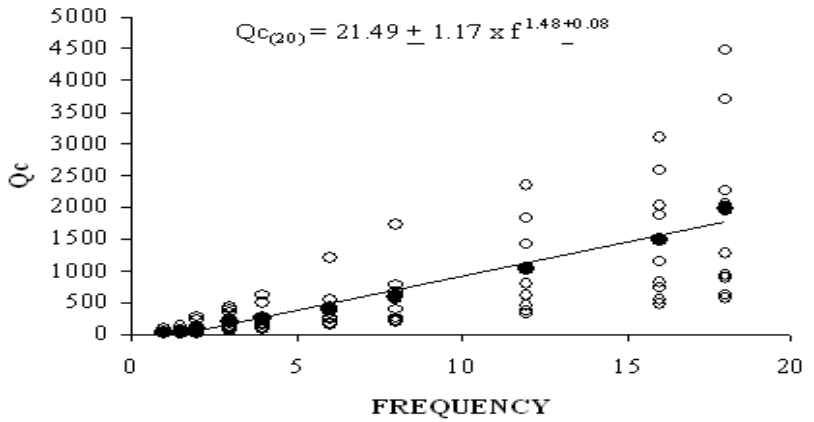

Figure 5a. Shows the distributions of $\mathrm{Q}_{\mathrm{c}}$ values with frequency for coda window lengths 20 seconds

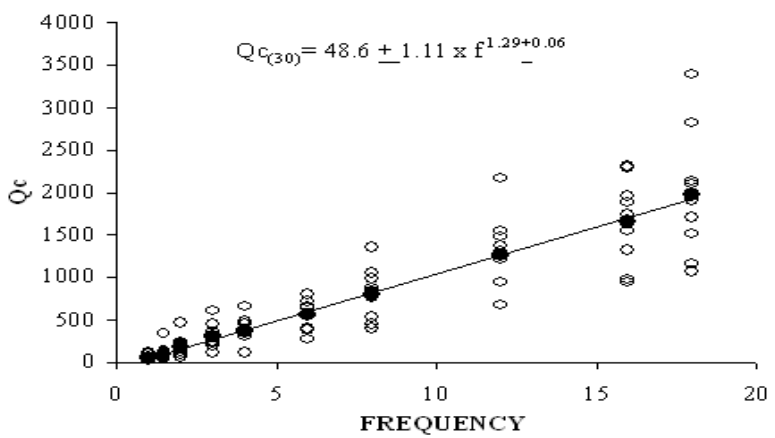

Figure 5b. Shows the distributions of $\mathrm{Q}_{\mathrm{c}}$ values with frequency for coda window lengths 30 seconds

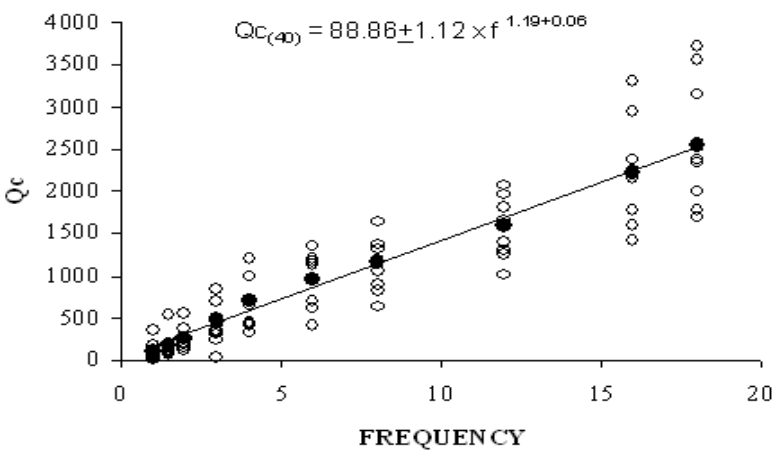

Figure 5c. Shows the distributions of $\mathrm{Q}_{\mathrm{c}}$ values with frequency for coda window lengths 40 seconds

From the above results it is observed that $\mathrm{Q}_{\mathrm{c}}$ values obtained for the seismograms are highly frequency dependent. The $Q_{c}$ values increases with increase in frequency. The high frequency dependent characteristics of the $Q_{c}$ values may be due to different heterogeneity present in the propagating media. Aki(1980) observed that only highly fractured media can generate frequency dependent $Q_{c}$ values. Moreover it is observed that $\mathrm{Q}_{\mathrm{c}}$ value increases with increase in coda window length. The variation $Q_{c}$ values with lapse time is plotted in Figure 6. The degree of frequency dependence ' $n$ ' is almost constant whereas $Q_{o}$ values are increasing with increase in lapse time coda window length. The higher lapse time of coda window samples larger area of the earth's crust covering the deeper part. The $\mathrm{Q}_{\mathrm{c}}$ value increases with depth implies that attenuation is decreasing with depth. This may be due to the fact that homogeneity increases with depth.

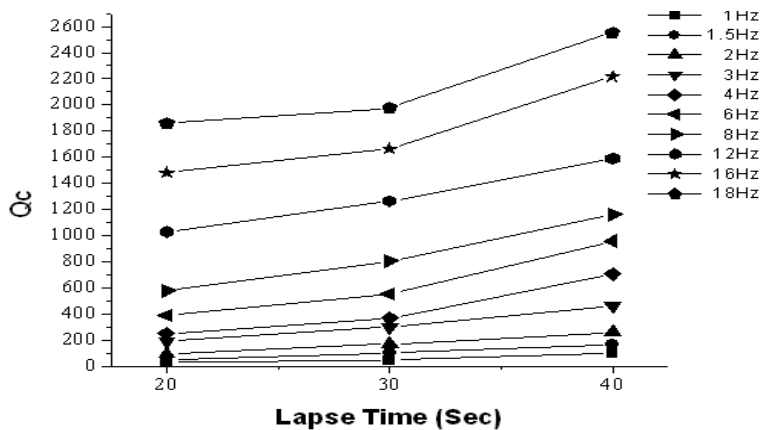

Figure 6. Figure showing the variation of Qc values with lapse time of coda window length

\section{Conclusions}

This study suggests that $Q_{c}$ values are frequency dependence in the media through which it propagates. The value of frequency dependence $n(>1)$ suggests that the media is not homogeneous. Since the media is non-homogeneities, intrinsic and scattering mechanism takes place causing the attenuation of the coda wave amplitudes. Attenuation decreases with depth may indicating that deeper part of the earth's crust is comparatively homogeneous than the upper most crust.

\section{ACKNOWLEDGEMENTS}

Hearty thanks to Dr. Debajit Hazarika, Scientist - B, Wadia Institute of Himalayan Geology, Dehradun for the intensive support in data analysis and interpretation. I extent my thanks to all the Teaching staff of the Department of Mathematical Science, Tezpur University, Tezpur for their valuable support during my works. I would like to thank the Director, School of Petroleum Technology, Gandhinagar for his support in this work. Finally special thanks to all my family members for their valuable support in my works.

\section{REFERENCES}

[1] Frankel, A., McGarr, A., Bicknell, J., Mori, J., Seeber, L., Cranswick, E., 1990. Attenuation of high-frequency shear wavesin the crust: measurements from New York State, South Africaand Southern California: J. Geophys. Res. 95, 17441-17457

[2] Aki, K. (1969). Analysis of seismic coda of local earthquakes as scattered waves: J. Geophys. Res. 74, 615-631

[3] Aki, K. (1973). Scattering of P waves under the Montana Lasa: J. Geophys. Res. 78, 1334-1246 
[4] Aki, K. (1980). Attenuation of shear-waves in the lithosphere for frequencies from 0.05 to $25 \mathrm{~Hz}$ : Phys. Earth Planet. Inter. $21,50-60$

[5] Aki, K., and Chouet, B. (1975). Origin of coda waves: Source, attenuation andscattering effects: J. Geophys. Res. 80, $3322-3342$

[6] Aki, K. and Richards, P. (1980). "Quantitative Seismology Theory and Methods" Vols. 1 and 2, W. H. Freeman, San Francisco

[7] Al-Shukri, H. J. and Mitchell, B. J. (1990). Three dimensional attenuation structure in and around the New Madrid seismic zone: Bull. Seismol. Soc.Amer., 80, 615-632

[8] Benites, R., Aki K., and Yomogida, K., (1992). Multiple scattering of $\mathrm{SH}$ waves in 2-D media with many cavities: Pure Appl. Geophys. 138, 353-390

[9] Benites, R. A., Roberts, P. M., Yomogida K., and Fehler, M. (1997). Scattering of elastic waves in 2-D composite media I. Theory and test: Phys. Earth Planet Inter., 104, 161-173

[10] Berteussen, K. A. (1975). Crustal structure and P-wave travel time anomalies at NORSAR: J. Geophys. 41, 71-84

[11] Biswas, N. N., and Aki, K., (1984). Characteristics of coda waves, Central and south central Alaska,:Bull. Seismol. Soc. Am. 74, 493-507

[12] Capon, J. (1974). Characterization of crust and upper mantle structure under LASA as a random medium, Bull. Seismol. Soc. Am. 64, 235-266

[13] Capon, J., and Berteussen, K. A. (1974). A random medium analysis of crust and upper mantle structure under NORSAR: Geophys. Res. Lett. 1, 327-328

[14] Fang, Y., and Müller, G. (1996). Attenuation operators and complex wave velocities for scattering in random media: Pure Appl. Geophys. 148, 269-285

[15] Fehler, M., Roberts, P., and Fairbanks, T. (1988). A temporal change in coda wave attenuation observed during an eruption of Mount St. Helens: J. Geophys. Res. 93, 4367-4373

[16] Fehler, M., Hoshiba, M., Sato, H., and Obara, K. (1992). Separation of scattering and intrinsic attenuation for the Kanto-Tokai region, Japan, using measurements of S-wave energy versus hypocentral distance: Geophys. J. Int.108, $787-800$

[17] Flatté, S. M., and Xie, X.-B. (1992). The transverse coherence function at NORSAR over a wide range of separations: Geophys. Res. Lett. 19, 557-560

[18] Flatté, S. M., and Wu, R.-S. (1988). Small-scale structure in the lithosphere and asthenosphere deduced from arrival-time and amplitude fluctuations at NORSAR: J. Geophys. Res. 93, 6601-6614

[19] Frankel, A., and Clayton, R. W. (1986). Finite difference simulations of seismic scattering: Implications for the propagation of short-period seismic waves in the crust and models of crustal heterogeneity: J. Geophys. Res. 91, 6465-6489

[20] Frankel, A., and Wennerberg, L. (1987). Energy-flux model of seismic coda: Separation of scattering and intrinsic attenuation: Bull. Seismol. Soc. Am. 77,1223-1251

[21] Gazdag, J., and Sguazzero, P. (1984). Migration of seismic data by phase-shift plus interpolation: Geophysics, 49, 124-131

[22] Got, J. L., Poupinet, G., and Fréchet, J. (1990). Changes in source and site effects compared to coda $\mathrm{Q}^{-1}$ temporal variations using microearthquakes doublets in California: Pure Appl. Geophys. 134, 195-228

[23] Gusev, A. A., and Abubakirov, I. R. (1996). Simulated envelopes of nonisotropically scattered body waves as compared to observed ones: another manifestation of fractal heterogeneity: Geophys. J. Int., 127, 49-60

[24] Hartse, H., Phillips, W. S., Fehler, M. C., and House, L. S. (1995). Single-station spectral discrimination using coda waves: Bull. Seismol. Soc. Am. 85, 1464-1474

[25] Hoshiba M. (1993). Separation of scattering attenuation and intrinsic absorption in Japan using the multiple lapse time window analysis of full seismogram envelope: J. Geophys. Res. 98, 15809-15824

[26] Jackson, D. D., and Anderson, D. L. (1970). Physical mechanisms of seismic wave attenuation: Rev. Geophys. Space Phys. 8, 1-63

[27] Kawahara, J., and Yamashita, T. (1992). Scattering of elastic waves by a fracture zone containing randomly distributed cracks: Pure Appl. Geophys. 139, 121-144

[28] Kikuchi, M. (1981). Dispersion and attenuation of elastic waves due to multiple scattering from cracks: Phys. Earth Planet. Inter. 27, 100-105

[29] Igor B. Morozov (2011), Temporal variations of coda Q, an attenuation-coefficient view: Physics of the Earth and Planetary Interiors 187 (2011) 47-55, doi:10.1016/j.pepi.2011.04.012

[30] Xie, J., 2010. Can we improve estimates of seismological Q using a new "geometrical spreading" model? Pure Appl. Geophys. 167, 1147-1162, doi: 10.1007/s00024-010-0188-8

[31] Xie, J., Fehler, M., 2009. Comment on 'Thirty years of confusion around 'scattering $Q$ '?' by Igor B. Morozov, Seismol. Res. Lett., 80, 646-647

[32] Morozov, I. B., Zhang, C., Duenow, J. N., Morozova, E. A., Smithson, S., 2008. Frequency dependence of regional coda $Q$ : Part I. Numerical modelling and an example from Peaceful Nuclear Explosions: Bull. Seism. Soc. Am., 98, 2615-2628, doi: $10.1785 / 0120080037$

[33] Carcolé, E., Ugalde, A., 2008. Formulation of the multiple non-isotropic scattering process in 2-D for nonspherical source radiation,: Geophys. J. Int., 174, 1037-1051

[34] Cormier, V. F. (2011). Seismic viscoelastic attenuation, in: Gupta, H. K. (Ed.), Encyclopaedia of Solid Earth Geophysics: Springer, doi: 10.1007/978-90-481-8702-7, 1279-1289

[35] Greenberg, R. (2009). Frequency dependence of tidal Q: Astron. J., 698, L42-L45

[36] Mitchell, B. (2010). Prologue and invitation to participate in a forum on the frequency dependence of seismic Q: Pure Appl. Geophys. 167, 1129, doi 10.1007/s00024-010-0180-3

[37] Morozov, I. B. (2008). Geometrical attenuation, frequency dependence of Q, and the absorption band problem: Geophys. J. Int., 175, 239-252 